\title{
PAPILLOEDEMA, OPTIC ATROPHY, AND BLINDNESS DUE TO EMPHYSEMA AND CHRONIC BRONCHITIS*
}

\author{
BY \\ BERNARD J. FREEDMAN \\ Dulwich Hospital, London
}

PAPILlOEDEMA occurring in association with pulmonary emphysema was first described by Cameron (1933). Simpson (1948) reporting three cases, thought it rare. Westlake and Kaye (1954) reported three cases in twelve emphysematous subjects, ten of whom had raised intracranial pressure. Flint (1954), describing the clinical features of a series of patients with cor pulmonale most of whom had emphysema, found papilloedema in nine out of seventy whose fundi were examined. Leggat (1958) reported one case and pointed out that papilloedema may persist after hypercapnia has subsided.

Taking all cases of emphysema, the occurrence of papilloedema is rare, but amongst those who are disabled by it, "uncommon" would probably be a more appropriate term. The case report which follows appears to be the first in which blindness has been described, although it is noteworthy that Cameron (1933) remarked that "the consecutive optic atrophy is likely to lead to blindness."

\section{Case Report}

A 44-year-old lorry-driver, first admitted to Dulwich Hospital in 1954, remained under observation through several admissions linked by out-patient attendances until his death 6 years later. Apart from pneumonia in childhood from which recovery was complete, his early history was not significant. In 1941, at the age of 31, while serving in the Army in the Middle East, he began to have mild attacks of wheezing and sweating, without cough or sputum, which lasted a few hours and recurred at roughly fortnightly intervals. After 6 years these attacks ceased. Henceforth he was prone to wheeze and cough during the winter and in rainy weather; sputum was scanty; fog did not trouble him. He smoked thirty cigarettes a day. He stated that effort tolerance was little if at all impaired, but without doubt he must have minimized his symptoms.

He was admitted on November 26, 1954 with a 3 weeks' history of cough and shortness of breath on exertion. Clinically he was suffering from a severe acute exacerbation of chronic bronchitis with advanced emphysema. He exhibited deep cyanosis, fingerclubbing, and marked bilateral papilloedema, with dilatation of the retinal veins and circumpapillary haemorrhages. Visual acuity with glasses was: 6/12-1 in the right eye and 6/9-2 in the left. The heart was enlarged but there were no signs of congestive cardiac failure, normality of venous pressure being confirmed by direct measurement. The cerebrospinal fluid (C.S.F.) pressure was $300 \mathrm{~mm}$. The fluid on this and all other occasions was clear, colourless, sterile, and free from cytological or chemical abnormality. At no time during the 6 years during which he was under observation were there any other abnormal signs in the central nervous system suggestive of a space-occupying lesion, or any evidence of renal disease or hypertension. He was treated with oxygen and antibiotics.

* Received for publication August 8, 1962. 
The following investigations were undertaken soon after recovery from the acute stage.

Chest Radiograph: Hyperaemic lung fields and emphysema. Generalized cardiac enlargement.

Arterial $\mathrm{O}_{2}$ Saturation: Varied between 78 and 85 per cent.

Blood: Haemoglobin $19 \mathrm{~g} . / 100 \mathrm{ml}$; haematocrit (venous) 68 per cent.; blood volume 8.52 1 . (Evans blue method, with correction for body/venous haematocrit ratio); red cell volume 5.201 .

Ventilatory Capacity*: Markedly reduced with prolongation of expiration.

$\mathrm{FEV}_{1 \cdot 0}=0 \cdot 80$ 1. (24 per cent. of expected).

$F V C=2.051$. FE ratio $=39$ per cent. (normal average $=83$ per cent.).

Facilities for measurement of arterial $\mathrm{CO}_{2}$ tension were not available at this time.

C.S.F. Pressure: $650 \mathrm{~mm}$., settling to $300 \mathrm{~mm}$. in 5 minutes. Inhalation of oxygen was followed by a prompt rise to $560 \mathrm{~mm}$. settling in 15 minutes to $270 \mathrm{~mm}$.

Electrocardiogram: Cor pulmonale; large R in V1; inverted T in V2 and V3.

Frequent recurrences of bronchial infection and continuing severe pulmonary insufficiency kept him in hospital for 17 months. Various organisms were grown from the sputum in each relapse, and corresponding changes in antibiotic therapy were made. At no time during the first 4 years was there any rise in jugular venous pressure (J.V.P.) or other clinical signs of cardiac failure. Signs of cor pulmonale regressed as shown by a reduction in the transverse diameter of the heart shadow from 16.6 to $12.8 \mathrm{cms}$., and reversal of the $\mathrm{R}$ - and $\mathrm{T}$-wave abnormalities in the electrocardiogram. The cyanosis, polycythaemia, and papilloedema, however, remained unchanged.

Eight months after discharge he was re-admitted (December 31, 1956) because of increasing disability and severe reduction of effort-tolerance. Objective confirmation of his deterioration was observed in a further fall in $\mathrm{FEV}_{1.0}$ to 0.591 . (18 per cent. of expected volume). He was treated with oxygen and antibiotics and given isoprenaline sulphate aerosol inhalations, to which he responded well, and a 4 weeks' course of prednisolone which yielded a slight increase in $\mathrm{FEV}_{1.0}$ but no obvious clinical benefit. The papilloedema and visual acuity were unaltered.

In May, 1958, the papilloedema was somewhat worse, and Mr. G. C. Pritchard reported as follows on the fundi:

"Mushroom swelling of both optic discs-right 3 dioptres, left 5 dioptres; considerable congestion of the veins, and a haemorrhage in the right eye."

The visual acuity with glasses was now only $6 / 36$ in the right eye and 6/18 in the left. In September there was less disc swelling but the veins were still very congested.

Signs of cardiac failure appeared for the first time in November, 1958, with recurrence of cardiac enlargement and electrocardiographic evidence of cor pulmonale. The oedema responded variably to mersalyl, chlorothiazide, and digitalis, and finally subsided 2 months later with acetazolamide and urea. Frequent intramuscular injections of nikethamide had no noticeable effect on the pulmonary ventilation or cyanosis. During the same month his vision deteriorated rapidly. He could no longer read a newspaper and towards the end of the month lost all useful vision, retaining only perception of light in the extreme left lateral field. A neurosurgeon expressed the view that, in the absence of severe headache or other disabling neurological disorder, his poor general condition did not warrant the risk of craniotomy. The C.S.F. pressure was now $530 \mathrm{~mm}$. Nikethamide $2 \mathrm{ml}$. $(0.5 \mathrm{~g}$.) was given 2-hrly for 2 days, after which the C.S.F. pressure was $315 \mathrm{~mm}$. The J.V.P. remained at zero level.

In April, 1959, the optic fundi were essentially unchanged, showing papilloedema, gross venous congestion, a few haemorrhages, and exudates at the macula. He was now

* Forced expiratory volume in $1 \mathrm{sec}$. $\left(\mathrm{FEV}_{1.0}\right)$ is the volume expired during the first second of a forced expiration after a maximal inspiration. Normal values for forced vital capacity (FVC) are taken from Needham, Rogan, and McDonald, (1954). Normal values for FEV $_{1.0}$ are taken as 83 per cent. of normal FVC (Tiffeneau, Bousser, and Drutel, 1949; Gaensler, 1951; Pemberton and Flanagan, 1956; and Miller, Johnson, and Wu, 1959).

FE ratio $=$ FEV/FVC. 
totally blind. In July of that year there was "very much less venous congestion but the discs were full of pale glial tissue" (Mr. G. C. Pritchard).

During the years 1957 to 1960 inclusive, he continued to have recurrent bronchial infections. His severely reduced effort tolerance, limited to walking slowly to 40 yards on the level, remained about the same during remissions. During 1960 he was in cardiac failure much of the time, and at all times deeply cyanosed and polycythaemic, with fingerclubbing, generalized pigmentation, and consecutive optic atrophy with total blindness.

Blood: Haemoglobin 17.1 g./100 ml.; haematocrit (venous) 68 per cent.

Arterial $\mathrm{O}_{2}$ Saturation: 81 per cent.

Arterial $\mathrm{PCO}_{2}: 78 \mathrm{~mm}$. $\mathrm{Hg}$; (normal $=40 \pm 5 \mathrm{~mm}$. $\mathrm{Hg}$ ), measured by the method of Campbell and Howell $(1959,1960)$.

$\mathrm{FEV}_{1.0}=0.571$. (18 per cent. of expected).

C.S.F. Pressure: $260 \mathrm{~mm}$.

Unexpectedly, on November 30,1960 , he vomited and had a convulsion; he appeared to regain consciousness but died 8 hours later.

\section{Post mortem Findings}

DR. F. Dische: Severe generalized diffuse emphysema; a small amount of emphysema of centrilobular type in the apices; several areas of old fibrosis, up to $2 \times 1 \mathrm{~cm}$., mainly subpleural in position; numerous emphysematous bullae of various sizes. Liver 1,770 g., one cough furrow, a few patches of yellow fatty change. Spleen moderately enlarged. Kidneys considerably enlarged (left 230 g., right 215 g.). Generalized congestion of all organs which bled freely on cutting (abridged).

DR. J. B. BRIERLEY: Brain strikingly congested. No uncinate herniation; moderate tonsillar coning, greater on the right than the left. Mamillary bodies symmetrical but small. Both optic nerves thin and greyish on section. No structural abnormality in cerebrum or cerebellum, apart from gross vascular congestion. Tegmental region patchily grey in medulla and uniformly grey in the outer cortical layers most marked in the floor of the sulci (abridged).

Prof. Norman Ashton (Left Eye):

Macroscopic examination.-The eye was opened horizontally to reveal neuroretinal oedema, corrugation of the vessels, particularly of the veins, and numerous small haemorrhages (probably micro-aneurysms) in the anterior half of the eye. A piece of retina was removed and the vessels were isolated by trypsin digestion. The specimen showed that the capillaries at the retinal periphery were entirely devoid of nuclei, both endothelial and intramural. Towards the equator endothelial nuclei suddenly reappeared and were about two to three times more numerous than normal; here also there was scattered pyknotic nuclear material. Many atrophic anuclear capillaries were present throughout the specimen, often in sharply demarcated foci. Intramural cells (pericytes) were absent throughout. Several fusiform and a few berry aneurysms were present on the capillaries particularly at the periphery.

Microscopic Examination.-Apart from some post mortem autolysis the only significant pathological changes to be seen in this eye were confined to the retina and optic nerve (Figure, opposite). The optic disc itself was markedly atrophic and showed evidence of old oedema, with cystic spaces either empty or filled with faintly eosinophilic material. There was glial replacement of the atrophied nerve fibres and the gliosis extended into the whole length of the atrophic nerve. In the 


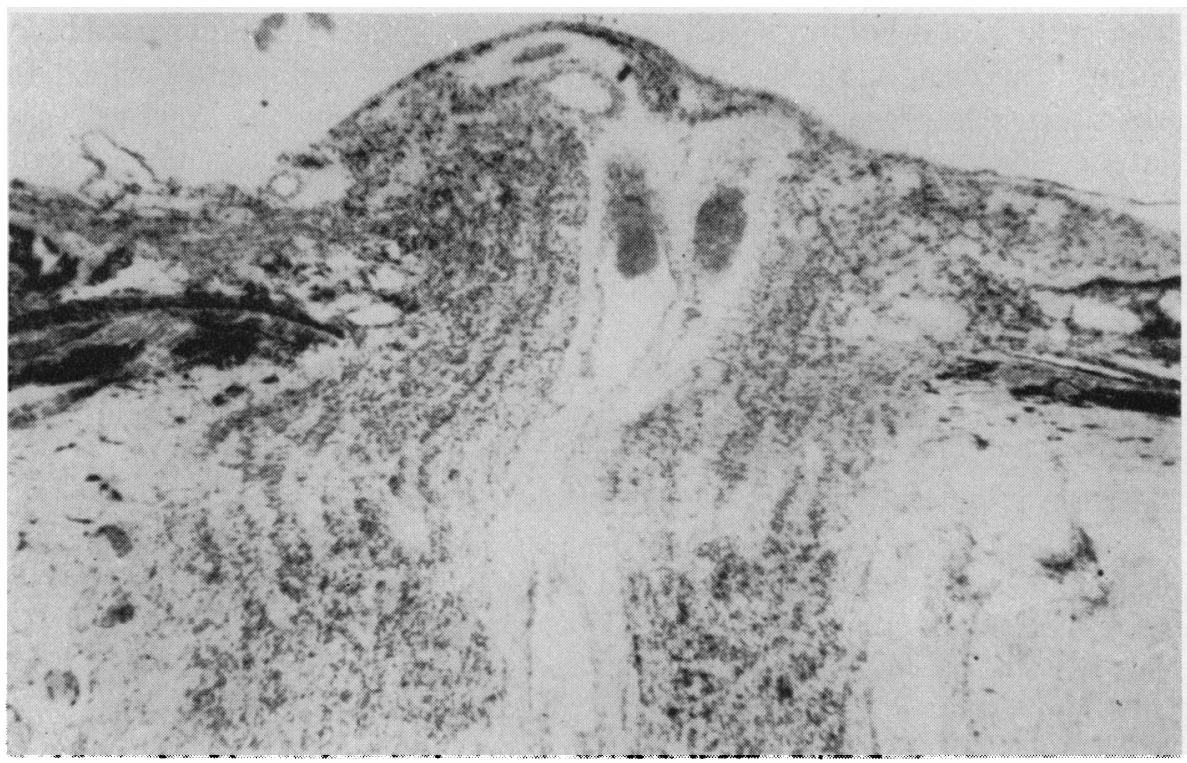

FIGURE.-A markedly atrophic optic disc with cystic spaces either empty or filled with faintly eosinophilic material - a residuum of past oedema. There is also gliosis within the disc and the nerve (N. Ashton).

retina there was still some oedema in the outer molecular layer with extensive loss of ganglion cells. Advanced arteriolosclerosis was evident in the central retinal artery and dilated capillaries could be seen at the retinal periphery.

Summary.-Advanced optic atrophy following neuroretinal oedema. Peripheral retinal microaneurysms and endothelial proliferation.

\section{Discussion}

The cause of raised intracranial pressure in severe emphysema has been discussed by Westlake and Kaye (1954). Inhalation of $\mathrm{CO}_{2}$ is followed very promptly by a rise in C.S.F. pressure due to intracranial vasodilatation (Kety and Schmidt, 1948). There seems to be no reasonable doubt that hypercapnia (raised arterial carbon dioxide tension) plays a major role in raising the intracranial pressure in advanced emphysema.

The role of anoxia is less certain. Acute anoxia causes a fairly prompt rise in C.S.F. pressure but there is no evidence that this occurs with chronic anoxia alone. It does not, for example, complicate cyanotic congenital heart disease in which hypercapnia does not occur. Moreover, if a cyanosed hypercapnic emphysematous subject is relieved of his anoxia by breathing oxygen, the C.S.F. pressure may rise despite full oxygenation of the arterial blood, because ventilation falls and hypercapnia increases.

Chronic anoxia may, however, play a contributory role in emphysema. It stimulates erythropoiesis (Freedman and Penington, 1963) and the polycythaemia is associated with an increase in the number of circulating red-cells and 
a rise in the blood-volume (Shaw and Simpson, 1961). The increased blood volume is accommodated by a generalized vascular dilatation in which the cerebral vessels presumably take part, thus aggravating the cerebral vasodilatation due to hypercapnia. Polycythaemia also increases the viscosity of the blood. Behrman (1962) has drawn attention to the high venous flowresistance at the lamina cribrosa and to the retinal venous obstruction which ensues when the blood viscosity is raised.

A raised jugular venous pressure is not the cause of the papilloedema since it may be normal when the C.S.F. pressure is raised in emphysema and, conversely, a grossly raised J.V.P., such as occurs with superior vena caval obstruction, is not associated with papilloedema (Pickering, 1942).

There is good evidence that the sequence of events is as follows:

Severe emphysema $\rightarrow$ excessive narrowing of pulmonary airways during expiration and uneven ventilation within the lungs $\rightarrow$ hypoventilation $\rightarrow$ hypercapnia $\rightarrow$ cerebral vasodilatation $\rightarrow$ raised intracranial pressure $\rightarrow$ papilloedema.

Possibly chronic anoxia $\rightarrow$ polycythaemia $\rightarrow$ increased blood volume $\rightarrow$ aggravation of cerebral vasodilatation.

\section{Summary}

Papilloedema is an uncommon complication of severe emphysema. It is due to hypoventilation, hypercapnia, and cerebral vasodilatation, leading to a rise in intracranial pressure. High blood viscosity due to polycythaemia raises the retinal venous pressure. Hypervolaemia, due to chronic anoxia and polycythaemia, probably aggravates the cerebral vasodilatation. The case is reported of a 44-year-old man, in whom the papilloedema ultimately led to optic atrophy and blindness.

I should like to express my thanks to Dr. H. C. Smellie for help in the clinical management of the case and to Mr. G. C. Pritchard for reporting on the optic fundi. I am also greatly indebted to Dr. F. Dische, Dr. J. B. Brierley, and Prof. Norman Ashton for reporting on the post mortem findings. Apparatus was made available by a grant from the S.E. Metropolitan Regional Hospital Board.

\section{REFERENCES}

Behrman, S. (1962). Brit. J. Ophthal., 46, 336.

CAMERON, A. J. (1933). Ibid., 17, 167.

Campbell, E. J. M., and Howell, B. J. L. (1959). " "Symposium on pH and Blood Gas Measurement", ed. R. F. Woolmer, p. 101. Churchill, London.

FLINT, F. J. (1954). Lancet, 2, 51.

Freedman, B. J., and Penington, D. G. (1963). Brit. J. Haematol., 9, in the press.

GAENSLER, E. A. (1951). Amer. Rev. Tuberc., 64, 256.

KETY, S. S., and SCHMIDT, C. F. (1948). J. clin. Invest., 27, 484.

LEGGAT, P. O. (1958). Lancet, 1, 672.

Miller, W. F., Johnson, R. L., Jr., and Wu, N. (1959). J. appl. Physiol., 41, 157.

Needham, C. D., Rogan, M. C., and McDonald, I. (1954). Thorax, 9, 313.

Pemberton, J., and Flanagan, E. G. (1956). J. appl. Physiol., 9, 291.

Pickering, G. W. (1942). J. Mt Sinai Hosp., 8, 916.

Shaw, D. B., and Simpson, T. (1961). Quart. J. Med., 30, 135.

SiMPSON, T. (1948). Brit. med. J., 2, 639.

TIFFeneAU, R., Bousser, J., and DRUTEL, P. (1949). Paris méd., 137, 543.

Westlake, E. K. (1958). Postgrad. med. J., 34, 2.

- and KAYE, M. (1954). Brit. med. J., 1, 302. 